the Nature Conservancy. He has also a general interest in the application of mechanical and electronic aids in data processing and map making and has published an agricultural atlas of England and Wales with the aid of the University of London computer and in collaboration with the Department of Numerical Automation. Dr. Coppock will take up his appointment on January 1, 1966.

\section{U.K. Petroleum Statistics, 1963 and 1964}

THe United Kingdom Petroleum Industry Statistics for the years 1963 and 1964 have recently been published by the Petroleum Information Bureau on behalf of the U.K. Petroleum Industry Advisory Committee (U.K. Petroleum Industry Statistics : Consumption and Refinery Production, 1963 and 1964. Pp. 8. London. Petroloum Information Bureau, 1965). Some interesting and perhaps significant contrasts are revealed. In 1963 total consumption of all products (excluding deliveries for bunkers for ships engaged in foreign trade) was 55,692,382 tons; in $1964,61,199,662$ tons. This consumption was apportioned as between: aviation fuels, $2,238,000$ and $2,302,931$ tons ( 1963 and 1964 respectively); motor spirit, 9,044,378 and 10,011,922 tons; industrial spirits, 200,429 and 229,880 tons; white spirit, 139,955 and 142,654 tons; kerosene, $1,673,261$ and $1,468,218$ tons (burning oil) and 183,962 and 147,869 tons (vaporizing oil); derv fuel, $3,305,230$ and $3,636,469$ tons; gas, Diesel and fuel oils, $5,453,366$ and $6,001,368$ tons (gas/Diesel oil) and 22,704,005 tons and $24,804,792$ tons (fuel oil); lubricating oils and greasos, 1,003,482 and 1,081,440 tons; paraffin wax and scale, 52,438 and 58,797 tons; propane, 99,193 and 147,576 tons ; butane, 371,364 and 621,456 tons; methane, nil for 1963, 76,917 tons for 1964; bitumen, 1,314,429 and 1,491,291 tons; chemical feedstock, 2,706,351 and $3,126,828$ tons; light distillate feedstock, 900,330 and $1,347,312$ tons; refinery gases, 426,619 and 483,046 tons. Thus deliveries into consumption of these products, with the exception of kerosene, showed marked increases in 1964 over the preceding year. The figures for propane, butane, methane, chemical foedstock and light distillate feedstock for 1964 are significant of the rapidly expanding petrochemicals and gas industry.

\section{Czechoslovak Society of Arts and Sciences in the United States}

THE Czechoslovak Society of Arts and Sciences in the United States is a unique organization (Nature, 198, 944; 1963). Its 800 members, of whom one-third are teachers at various universities in the United States, are mostly emigrants from Czechoslovakia who have kept their interest in their home-land alive and burning. The Society held two congresses in the United States: one in Washington, D.C., in 1962, and one in New York in 1964. A recent book, The Czechoslovak Contribution to World Culture (edit. by Miloslav Recheigl, jun. Pp. 682. The Hague: Mouton and Co., 1965. Gld. 58.00), is based mainly on the papers presented at the first congress, but seventeen of the fifty-seven contributions were not presented. The subjects range far and wide over the spectrum of Czechoslovak culture, national and international, past and present. The book is divided into ten parts: literature and literary eriticism, linguistics, music and fine arts, history, political science and philosophy, sociology, economics, law, seience and technology, and Czechs and Slovaks abroad. The volume is concluded with a bibliography on Czechoslovak arts and sciences containing 1,318 references. Short biographies of the fifty-four authore and an index are also included. The individual contributions vary so much in scope and subject-matter that any reader can find an article or two touching directly on his field of interest. The book is neither an encyclopaedia nor an ordered treatise on Czechoslovakia. To a reader interested in all espects of Slavistics it can be highly recommended; to a student of Czechoslovakia it is invaluable. It is expected that a similar volume, based on the 1964 Congress of the Society, will be published in due course.

\section{Tumour Research}

VouUme VII, Fascicles 3 and 4 of the Archivo Italiano di Patologia e Clinica dei Tumori, is a beautifully printed and attractively produced volume containing 15 articles on various aspects of the study of tumours. The subjects dealt with include methods of producing experimental cerebral tumours resembling human brain tumours, and the morphological, biochemical and immunological proporties of these experimentally produced tumours, the difficulties of transplanting them and the promising future of this field of research. Two articles discuss the antitumoral activity of a series of biguanide derivatives tested on Ehrlich ascites tumour. Two articles discuss the effects of urethane on the cells of this tumour. Another article describes the morphological, biochemical and immunological properties of Ehrlich ascites tumour cells which have been submitted to several cycles of freezing and thawing. In a paper on the reliability of a technique for the early serodiagnosis of malignant neoplasia, which is based on identifying a typical phospholipid (malignolipin) in the serum, the authors conclude that Kosaki's technique obtains only a mixture of inorganic ions and picrates from the solvent, but no malignolipin. An article on the treatment of patients with malignant tumours with 2,3,5-triethyleniminobenzoquinone by different methods describes palliative effects on one group of patients with no serious side-effects. A second group showed no deaths in the first year, although deaths were recorded among the controls. The volume ends with an illustrated description of 5 cases of histologically benign tumours of the stomach (haomangio-endotheliomas, lipomas and adeno-papillomas and choristomas (aberrant pancreas)), and the author discusses the great difficulties in differentiating on clinical and radiological data betwoen benign blastomas, choristomas and malignant tumours. All the articles give copious references to the relevant literature.

\section{Transplantation Research}

THE size of the Proceedings of the sixth International Transplantation Conference (five times as thick as the first) is an indication of the attraction this subject has for research, but tho progress made so far in overcoming the basic problems of tissue incompatibility seems scarcely to justify its present-day popularity with experimental surgeons (Annals of the New York Academy of Sciences, $120,1-806 ; 1964)$. Perhaps the most intensive effort has been directed towards finding means of typing human tissues for histocompatibility, as by this it would become possible to pick from a panel of prospective donors that one whose tissue would be most likely to survive in the recipiont. Probably the most valuable tost in the long run will be an entirely in vitro reaction such as that of Bain et al., in which the blood lymphocytes of prospective donor and recipient are allowed to react together. A clinical section (Volume 2) deals largely with attempts to transplant a great many organs in man and animals. While it includes many interesting descriptions of surgical technique and of the pathology of the graftod organs during the rejection which almost invariably occurred, the value of the information obtained sometimes seems scarcely to justify the experiment-especially where human patients were involved. The ethics of such experiments are considered in a thoughtful survey of human kidney transplantation by Murray et al. Even in the few "well-tolerated" human kidney grafts described by Hamburger et al., there were recurrent crises which required treatment with immunosuppressive drugs. It thus appears that the presence of the grafted organ alone may not be sufficient to maintain the state of tolerance, 